\title{
THE UTILISATION OF INDUSTRIAL PROCESS MODELS IN ACQUIRING THE PRACTICAL SKILLS OF PLC PROGRAMMING
}

\author{
Beata Jakubiec \\ Czestochowa University of Technology, Faculty of Electrical Engineering Poland
}

\begin{abstract}
In the paper the use of process models and computer simulation as the tools which facilitates students to learn the conditions of the industrial processes control has been presented. Such approach enables to familiarise with operation and programming of controllers of industrial process. Moreover, it also enables safe testing of control algorithms provided by logic controllers through their implementation at the real industrial facility.
\end{abstract}

Keywords: process model, programmable logic controller, simulation.

\section{Introduction}

The correct implementation of automated engineering process shall require from the persons preparing particular stages of it to have specific knowledge including control, implementation of relevant algorithms and to have clearly defined tasks of supervision over operation of the production lines. Inherent part in the industrial technology is also to involve various means of transmissions and information processing. Therefore, preparation of the staff to the tasks imposed upon it forces the provision of adequate training not only within technical details of a particular process and its control but also regarding communication network interoperability between different system elements, both at normal operation and failure condition. The safe acquisition of such skills by the future technical staff is opportune due to the application at training students of relevant didactic tools provided in a form of models and simulation of controlled system or process (Olesiak, 2014; Podlejski \& Rak, 2007; Prauzner, 2016; Ptak, 2015).

\section{The structure of industrial systems}

The procedures for direct control of particular equipment of the process line as well as visualisation and supervision over such equipment are implemented within 1 level and 2 level of hierarchical structure of industrial systems, it means of the control system of industrial process, where the most common are Programmable Logic Controllers (PLC) and Supervisory Control And Data 
Beata Jakubiec. The Utilisation of Industrial Process Models in Acquiring the Practical Skills of PLC Programming

Acquisition system or Human Machine Interface (SCADA/HMI). Communication protocols of industrial automation (Modbus, Profibus, DeviceNet, etc.), until recently the closed systems, owing to the new possibilities which are offered by Ethernet, TCP/IP, GSM, GPRS technologies and due to their application to sensors, actuators, control systems and data acquisition systems allow the communication between them also via for example a web browser or a mobile phone. Therefore, the exchange of data, both in wired and wireless way, from controlled equipment as well as from PLC and SCADA layers and other external systems, including also between Manufacturing Execution System (MES) applied in production management network and management of the enterprise under the ERP system (Enterprise Resource Planning) is possible Figure 1 (Bognár \& Tóth, 2013; Liptak \& Eren, 2011; Wilamowski \& Irwin, 2016).

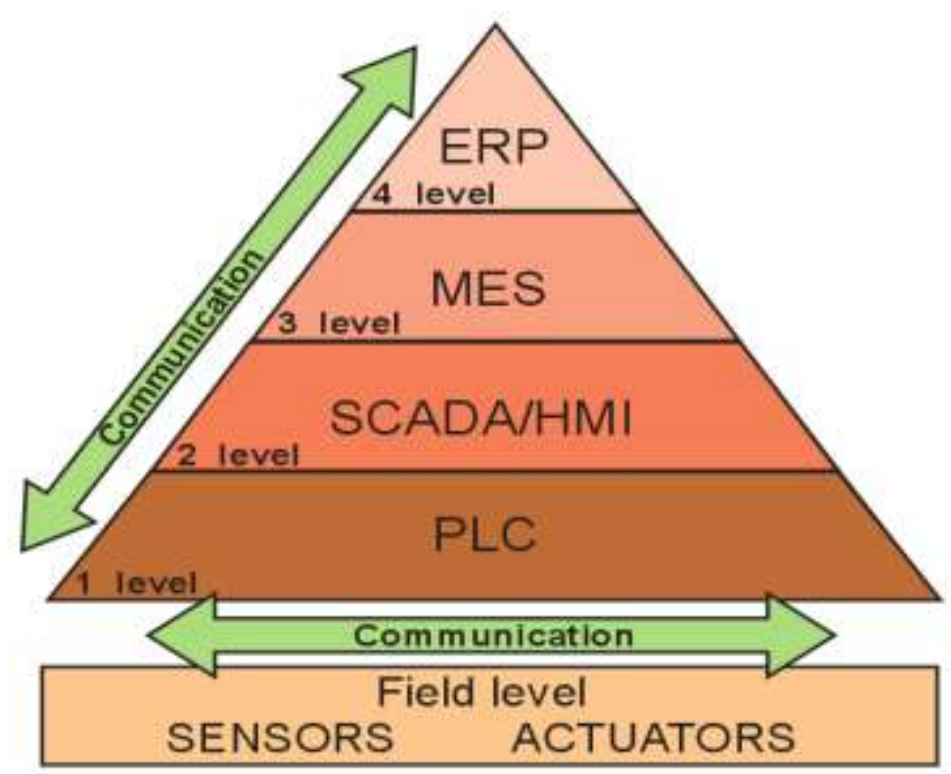

Fig.1 The communication layers in industrial systems

From the engineer designer and the later industrial system administrator's point of view, knowledge of the issues related to creation of control algorithms, programming and being aware of the specific engineering process and dynamics of control system elements. This will ensure relevant communication between particular control system elements which shall guarantee correct and failure-free production. Moreover, having the opportunity to analyse the configuration and to verify functioning and efficiency of the data transfer system (network simulators) and interoperability between the communication network and PLC control systems and the equipment of automation systems (sensors, encoders, inverters, valves, etc.) is also important. Carrying out tests on the operating technological process is usually for various reasons impossible and often even dangerous (e.g. potential to cause interruption to operation, equipment damage). Development of 
the model and simulation of a particular control process which reflect the real responses of the system is a solution to the issue. The simulation can be used at educating the staff as well as to test and learn new solutions, to improve the control quality, to analyse the reliability, or to develop the conduct procedures at failures and to mitigate their results.

\section{The concept of control process simulators}

Generally, several implementing arrangements of simulators intended to control system level, supervise and visualize the process can be identified. The simulator as close as possible to the industrial control system is a test facility consisting of a equipment providing the visualisation of the process (computer, operator panel) interoperable with logic controller and a model of the controlled system (Process Trainer) - Figure 2. That solution shall require developing a physical model of the process line, what depending on a degree of reflection accuracy of the real process (sensors, actuators) can involve significant financial costs. The SCADA software type is for example Asix, ControlMaestro, ICONICS, iFIX, InTouch, PROMOTIC, TRACE MODE, Vijeo Citect, WinCC.

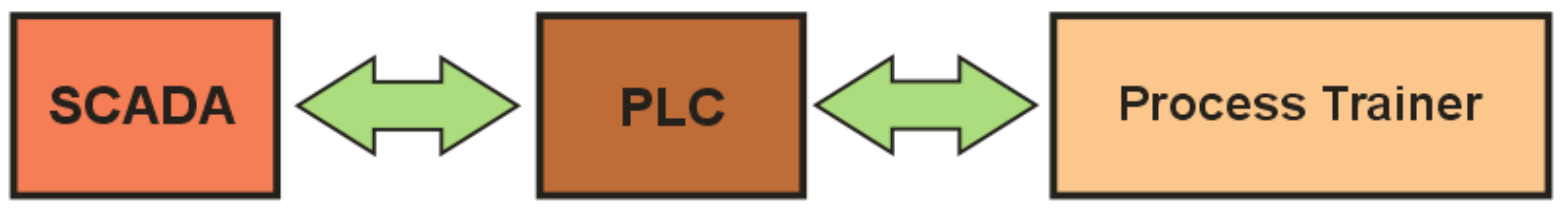

Fig. 2 The process computerised visualisation interoperable with the control system and the process physical model

Under laboratory conditions the facility model, for reasons of simplicity, may constitute a set of discreet and analogue programming devices which enables forcing positions at controller's inputs manually and monitoring its output positions - PLC Trainer (Fig. 3). Figure 4 and Figure 5 provide the examples of the physical model of the controlled system. The positions programming devices adjusted manually are presented in Figures 6 and 7.

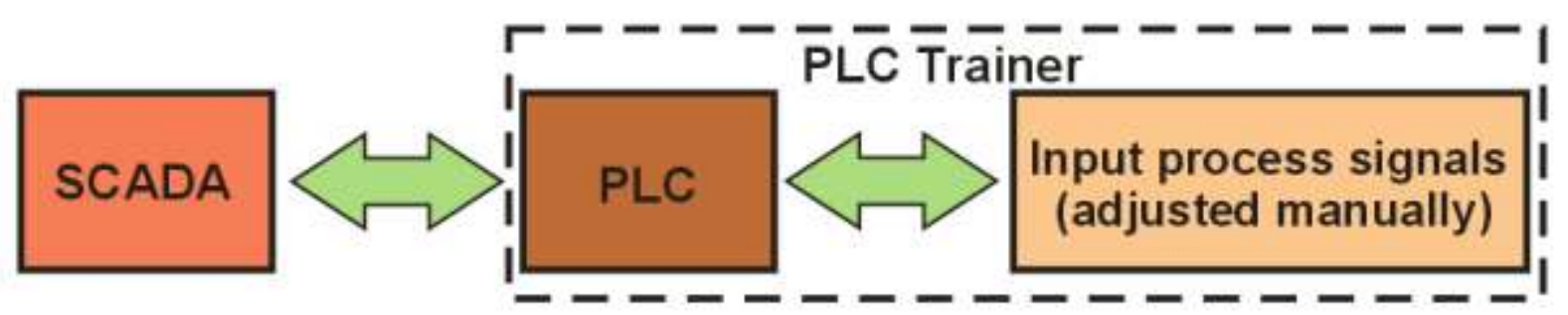

Fig.3 The process computerised visualisation interoperable with PLC Trainer 
Beata Jakubiec. The Utilisation of Industrial Process Models in Acquiring the Practical Skills of PLC Programming

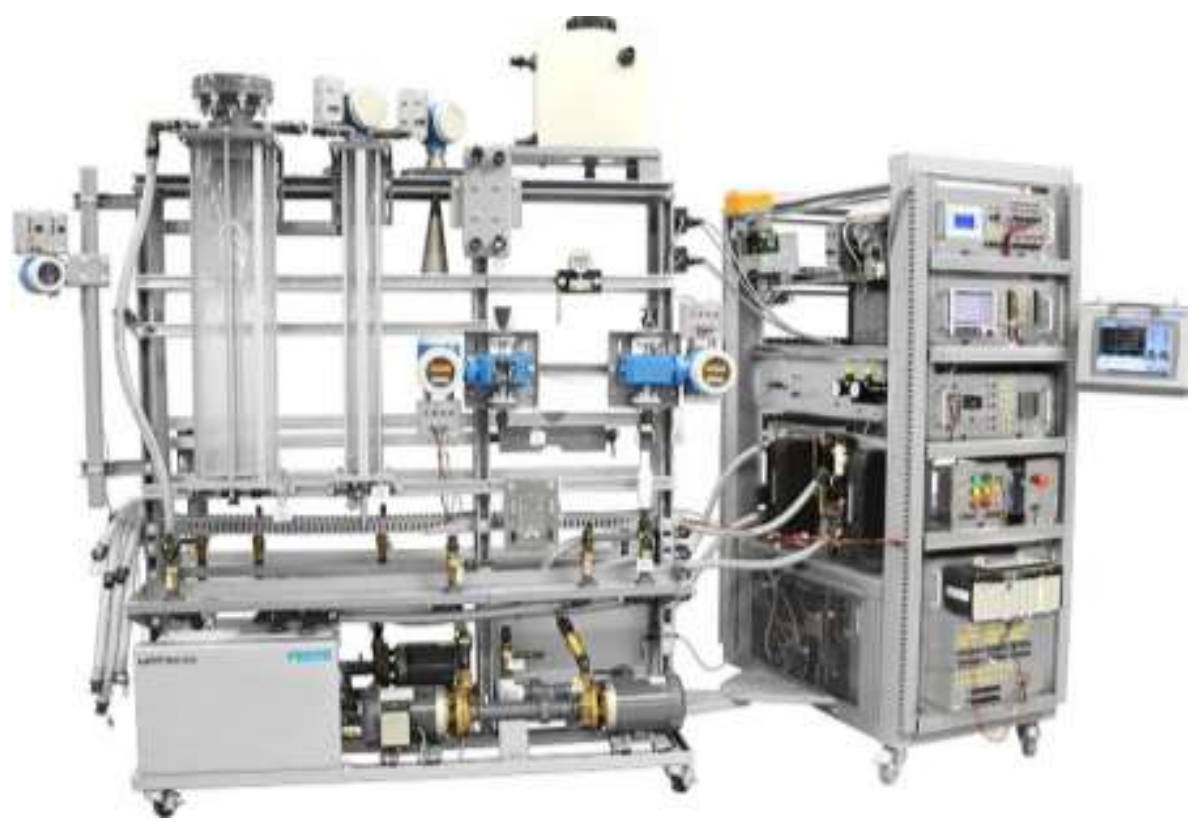

Fig.4 Pressure flow level and temperature process training system by Festo (LabVolt, 2017)

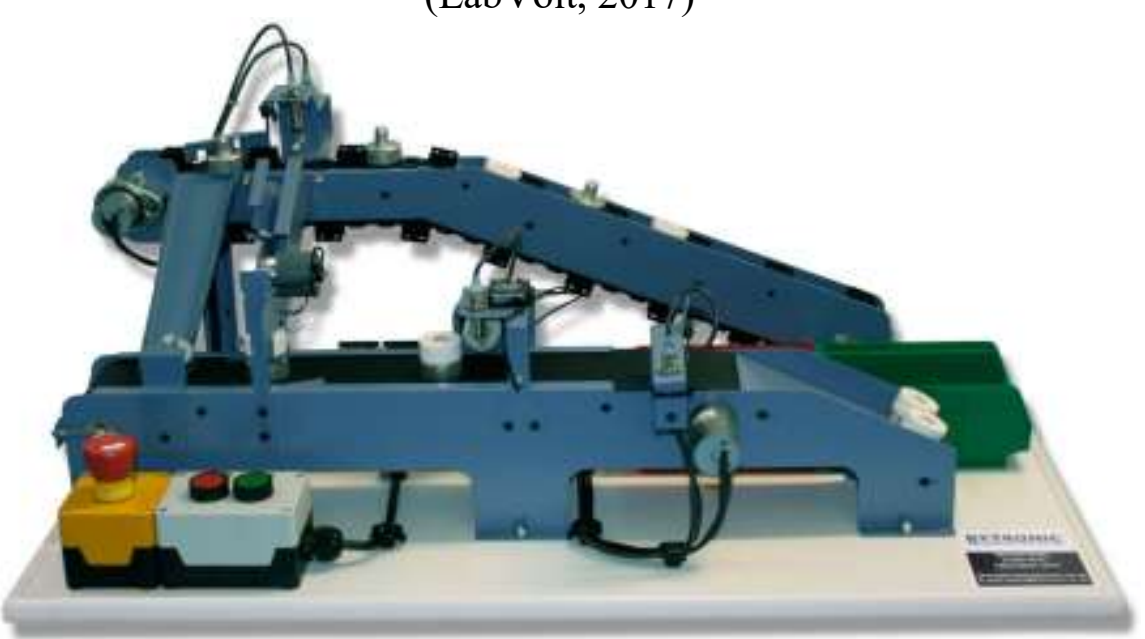

Fig.5 Industrial Control Trainer by Baytronic (Baytronic, 2017)

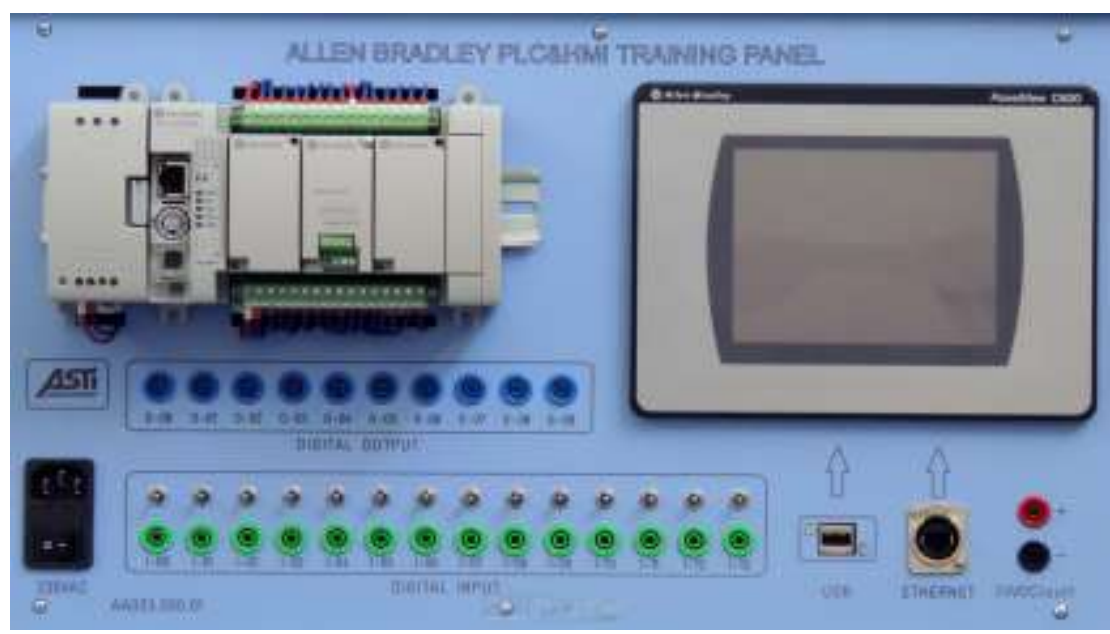

Fig.6. PLC Trainer by ASTI (ASTI, 2017) 


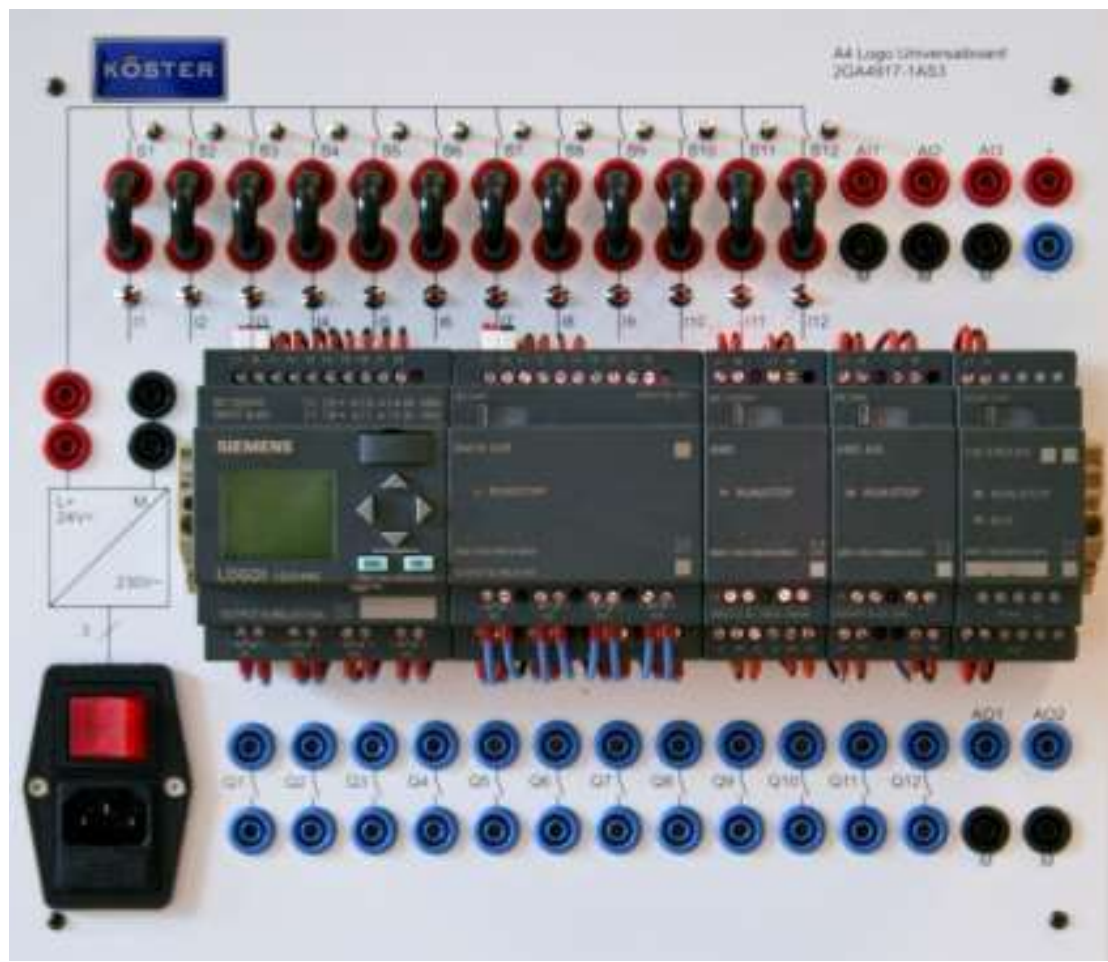

Fig.7 PLC Trainer by KOESTER (Encon, 2017)

The simulation set can be also composed of a process physical model controlled by PLC controller implemented on PC, an industrial computer or an advanced operator panel (PC-based controller). Such a software controller, so called softPLC (for example SIMATIC S7-1500 Software Controller, SIMATIC WinAC, TwinCAT), is nothing other than an application operating under control, for example of Windows system, which through industrial networks or I/O modules communicates and controls elements of the model - Figure 8. The undoubted advantage of such approach is considerable increase of computing power in relation to the standard industrial controllers. SoftPLC can be applied as independent environment, and any SCADA software can be used for graphic presentation of the process. The use of a packet which combines inter alia control functions, visualization and communication with signals acquisition systems can be another option e.g Automation Studio. It is also possible, due to the use of the programme and calculation environment for example LabVIEW software, which controls the process model by means of the multifunction I/O card, to apply the author's approach (Figure 9).

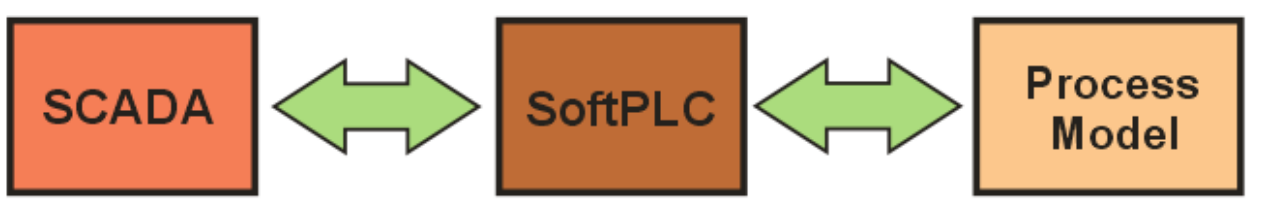

Fig. 8 The computer provided with SCADA and PC-based controller interoperable with a physical model of the facility 
Beata Jakubiec. The Utilisation of Industrial Process Models in Acquiring the Practical Skills of PLC Programming

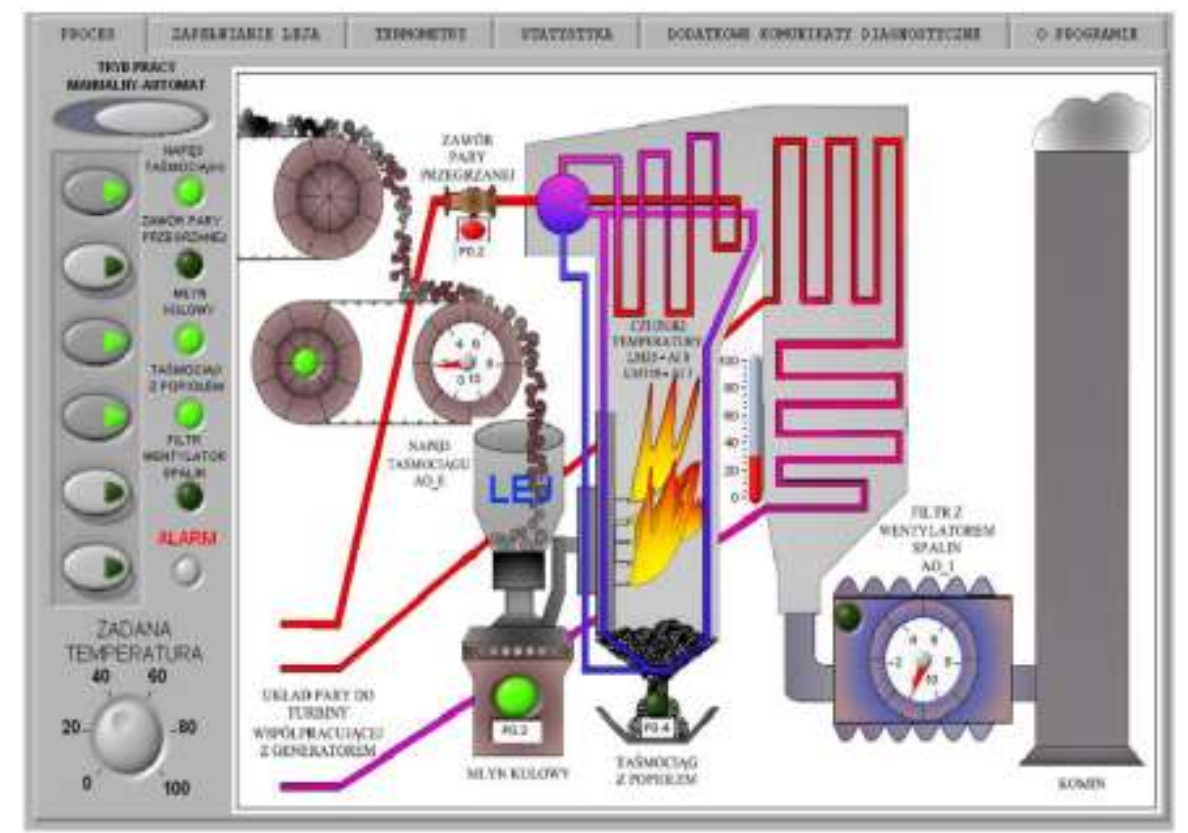

Fig.9 Visualisation of the superheated steam control process (Podlejski \& Rak, 2007)

In another type of the process simulator PLC controller shall read signals from virtual sensors and control virtual actuators. The facility has been modelled on the computer and it communicates with the logic controller. The entire process is visualised on the computer's monitor - Figure 10.

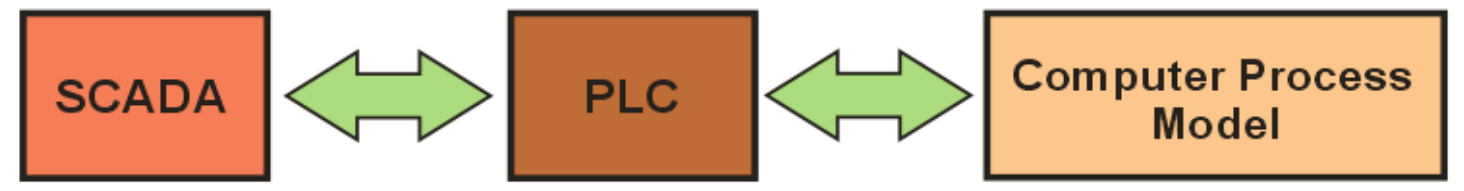

Fig.10 The physical control device connected with the computer model and process visualisation

The ones of computer process models are of a company, the most frequently closed to a user and/or dedicated merely to a particular process or a range of applied equipment, for e.g. ITS programme which offers virtual manufacturing processes. Figure 11 presents one of them. Another computer process model prepared individually by author are based on generally available programmes. They ensure high flexibility and openness of the structure. Mathematical models of the analysed issue are developed in the programme and calculation environment, for e.g. MATLAB, which can be also used to carry out a graphic picture of the process. The programmes of SCADA type can be also applied for visualisation of the modelled problem. 


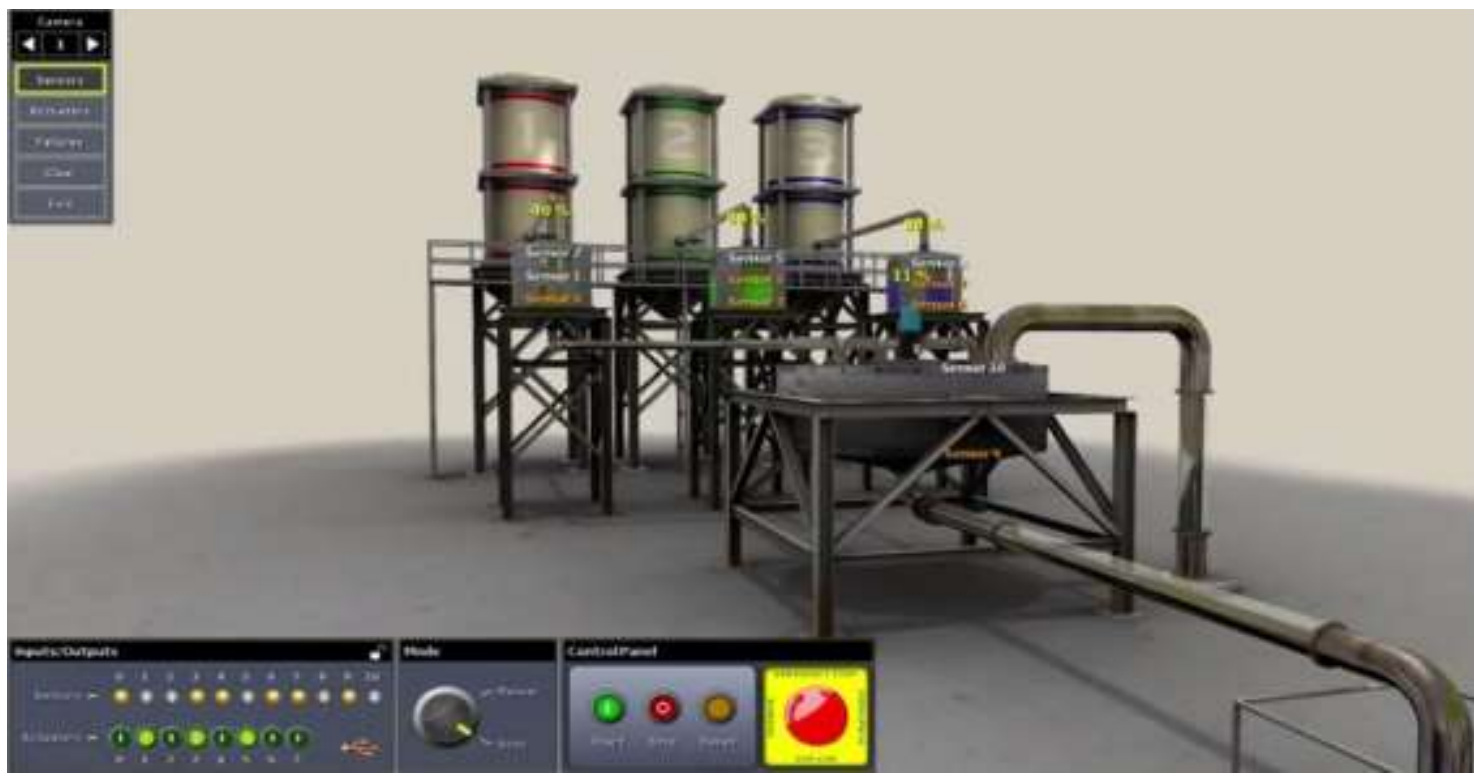

Fig.11 Simulation of the batch process (Encon, 2017)

A fully computerised simulator of the process, it means the IT system is a convenient type of the simulator. The IT system consists of computerised visualisation interoperable with dynamic models of the process, control systems, sensors and automation equipment. We are dealing here both with a virtual control object and a virtual PLC controller - Figure 12. On the market highly specialized simulation environments prepared for training within specific areas, e.g. Industrial Training Simulator by ABB, Operating Training Simulator by Honeywell, are available. Usually, the programmes are closed, what means a user may interfere in to them within a very limited range.

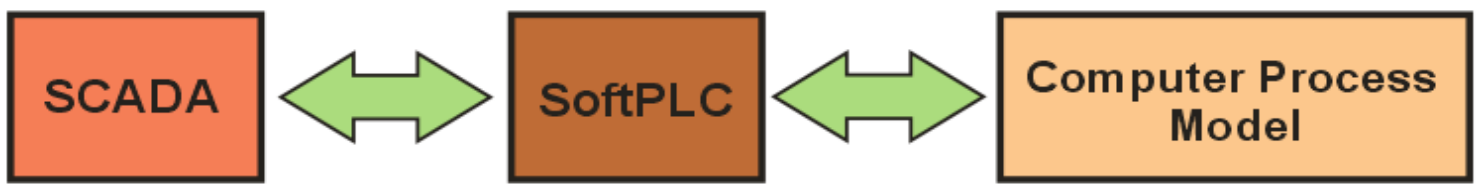

Fig. 12 The computerised visualisation interoperable with dynamic models of the process and control systems

In the event we intend to provide simulation of various processes and where we want to have the complete control over the simulator structure it shall be efficient to use generally available SCADA as well as softPLC software and independently develop appropriate applications. Then, the computerised simulators of controlled objects (e.g. developed at LabVIEW) should take into consideration the elements of sequence control and the dynamic parameters of the process. Both the object of control and a software controller are connected in to 
Beata Jakubiec. The Utilisation of Industrial Process Models in Acquiring the Practical Skills of PLC Programming

one network system of data exchange operating in the real time. It enables the effective analysis of the entire system, not only with regard to the quality of automotive control but also regarding consideration in this process of network performance, connected with the data exchange and visualisation.

\section{Conclusions}

The industrial processes simulators play an essential role in the process of education of new staff and professional training. Depending on specificity of the process which they are to reflect, their structure may take various forms. The application of a physical model of the object of control is a solution as close to the reality as possible. Unfortunately, from the scientific perspective of programming automation systems and industrial communication networks the solution is not optimal. The primary concern is to handle critical situations which may lead to damage the model. Insurance for safe use of the simulator itself shall be also required. In view of that, the use of the complete computerised simulator of the process seems to be applied. In order to reflect the real process the simulating algorithms shall include the completed times of response of sensors and controllers to the adjusted signals. However, such form of the simulator allows to serve critical emergency situations occurring due to operator's mistaken decisions or sudden loss of communication between the facility and the controller

\section{References}

ASTI Automation (2017). Didactic equipment from http://www.astiautomation.ro/

Baytronic (2017). Educational technology from http://www.bytronic.net/

Bognár, G., \& Tóth, T. (2013). Applied Information Science, Engineering and Technology: Selected Topics from the Field of Production Information Engineering and IT for Manufacturing: Theory and Practice. Springer Science \& Business Media.

Encon (2017). ITS PLC Professional from http://www.encon.pl

LabVolt (2017). Pressure flow level and temperature process training system. Festo Didactic from http://www.labvolt.com

Liptak, B. G., \& Eren, H. (2011). Instrument Engineers'Handbook: Process Software and Digital Networks, Fourth Edition, Tom 3, CRC Press.

Olesiak, K. (2014). Selected Problems of the Asynchronous Drive Control with the Three-phase Soft-start System. Proceedings of the Conference: Symposium on Mechatronics Systems, Mechanics and Materials, Jastrzebia Gora, Poland, October 09-10 2013, In: Mechatronic Systems, Mechanics And Materials II, Book Series: Solid State Phenomena, Vol. 210, pp 245-251.

Podlejski, K., \& Rak, J. (2007). Sterowanie procesem wytwarzania pary przegrzanej stanowisko dydaktyczne w LabVIEW. Prace Naukowe Instytutu Maszyn, Napędów $i$ Pomiarów Elektrycznych Politechniki Wrocławskiej Nr 60, Studia i Materiały Nr 27, 397-405. 
Prauzner, T. (2016). Interactive computer simulation as a response to contemporary problems of technical education. In: Society. Integration. Education, Proceedings of the International Scientific Conference. Volume II, May 27th - 28th 2016, Rèzekne, Latvia, pp. 579-588.

Ptak, P. (2015). Application of DasyLab in teaching electrical engineering. In: Society, Integration, Education, Proceedings of the International Scientific Conference. Volume IV, May 22th-23th 2015, Rēzekne, Latvia, pp. 490-499.

Wilamowski, B. M., \& Irwin, J. D. (2016). Industrial Communication Systems. CRC Press. 